\title{
COVID-19 and metabolic disorders: focus on the implicated molecular pathways
}

\author{
ersilia nigro $^{1}$, fabio perrotta ${ }^{2}$, rita polito ${ }^{2}$, vito d'agnano ${ }^{2}$, filippo scialo ${ }^{1}$, andrea bianco ${ }^{1}$, \\ and aurora daniele ${ }^{1}$ \\ ${ }^{1}$ Università degli Studi della Campania Luigi Vanvitelli \\ ${ }^{2}$ Università degli Studi del Molise
}

May 6, 2020

\begin{abstract}
Coronavirus disease (COVID-19) is caused by SARS-CoV2 virus, which causes serious respiratory illness such as pneumonia and lung failure. It was first reported in Wuhan, Hubei, China in December 2019 and rapidly spread globally, becoming a pandemic infection in March 2020. Although symptoms highly heterogenous (from absence of manifestations to severe respiratory acute failure), patients with metabolic associated diseases often resulted in worse COVID-19 outcomes. This study aims to investigate the association between metabolic diseases and COVID-19 severity, defining the possible molecular mechanisms that possibly determine the link between the two diseases and the worsening of COVID19 phenotype. In particular, we will define the role of the main biological processes that may function connecting metabolic alterations to SARS-CoV2 infection; hyperglycemia, immune system deregulation, ACE-2 receptor modulation, inflammatory response. The impact of metabolic disorders on the prognosis of COVID-19 have major implications in public health especially for countries affected by a high incidence of metabolic diseases.
\end{abstract}

\section{Comorbidities in SARS-CoV2 infection}

Initial data on SARS-CoV2 infection documented that patients with a background of pre-existing metabolic and cardiovascular diseases experienced unfavorable outcomes $(8,17)$. Although the influence of comorbidities in coronaviruses infections was previously reported during severe acute respiratory syndrome coronavirus (SARS-CoV), and Middle East respiratory syndrome coronavirus (MERS-CoV) outbreaks, the incidence is quite heterogenous $(18)(19)(20)(21)(22)(23)(10)(24)(25)$ (see table 1). Chronic cardiovascular disorders and diabetes mellitus were reported as the major comorbidities influencing prognosis during previous epidemic coronaviruses spread (26). A nationwide analysis on SARS-CoV2 in China reported a $25.1 \%$ prevalence of at least 1 comorbidity among 1.590 patients tested positive with SARS-CoV2. Authors found a proportion of $8.2 \%$ of diabetes, $16.9 \%$ of hypertension and $57.3 \%$ of other cardiovascular diseases (13). Likewise, comorbidities are highly prevalent among SARS-CoV2 patients who experience poorer clinical disease course. In Italy, according to the report of Istituto Superiore Sanità (ISS) based on available data on April 16th 2020, among patients with SARS-CoV2, the mean number of underlying diseases was 3.3 in 1,738 patients dying in-hospital, a single comorbidity in $14.4 \%$ patients, 2 comorbidities in $20.7 \%, 3$ or more in $61.3 \%$ patients. Among common comorbidities observed in SARS-CoV2 positive deceased patients, hypertension (69.7\%), type 2-diabetes $(32.0 \%)$ and ischemic heart disease $(27.7 \%)$ are the most frequent conditions(27). Li et al. highlighted in a recent metanalysis that the prevalence of hypertension, cardiovascular or cerebrovascular disease and diabetes were respectively $17.1 \%, 16.4 \%$ and $9.7 \%$, not higher compared to general population (28). However, they showed that the overall proportion of hypertension and diabetes was about two-fold higher in ICU/severe cases than in non-ICU/severe counterparts, although the difference did not reach the statistically significance (28). Similarly, Fadini et al. reported a metanalysis of 12 studies evidencing that 
although diabetes may not increase the risk of infection, the co-existence of this comorbidity among SARSCOV2 patients results in excess mortality (29).

During the 2009 influenza A virus H1N1 pandemic, obesity emerged as risk factor for symptom severity and mortality (30). Disproportionate adiposity may alter the interaction among the pulmonary microenvironment, viral pathogenesis and immune cell trafficking (31). Emerging data in SARS-CoV2 support the important role of obesity in influencing clinical outcomes. Lighter and coworkers focused the considerable impact of obesity in SARS-CoV2 patients aged $<60$ years. Based on 3.615 subjects tested positive, authors concluded that patients with a BMI between 30-34 were $2.0(95 \% 1.6-2.6, \mathrm{p}<0.0001)$ and $1.8(95 \%$ CI 1.2-2.7, $\mathrm{p}=0.006)$ times more likely to be admitted to acute department and ICU, respectively, compared to individual with a BMI $<30(25,32)$. However, the comprehensive mechanisms interacting between the virus-induced local inflammation and secondary reactive damage induced from excessive cytokine storm in patients with comorbidities are not fully clarified.

\begin{tabular}{llllll}
\hline & Diabetes & Hypertension & HD & Obesity & References \\
\hline SARS & $2.47-50.0 \%$ & $4.9-19.4 \%$ & $0.9-32.6 \%$ & - & $18-22$ \\
MERS & $32.4-68.0 \%$ & $28.9-34.0 \%$ & $7.5-28.0 \%$ & $17.0 \%$ & 10,23 \\
COVID - 19 & $14.3 \%$ & $26.3 \%$ & $16.9 \%$ & $20.7 \%$ & 24,25 \\
\hline
\end{tabular}

Tab. 1: COVID-19: Coronavirus disease 2019; HD: heart diseases; MERS: Middle East Respiratory Syndrome; SARS: Severe acute respiratory syndrome;

\section{Molecular mechanisms linking metabolic diseases and SARS-CoV2 infection}

It is plausible that more than one mechanism concurs in determining the relationship between metabolic diseases and SARS-CoV2 determining the elevated susceptibility to get the infection, as well as a worse prognosis of the disease. The factors mostly implicated seem to be: hyperglycemia, ACE-2 receptor modulation, hyperglycemia and immune system deregulation, inflammatory response.

Hyperglycemia, adipose tissue and immune response deregulation

Hyperglycemia has been associated not only with disease severity but also with death in patients with severe SARS-CoV2 (33). Interestingly, these findings are consistent with studies of patients infected with highly pathogenic avian influenza, as well as SARS and MERS whereby the presence of uncontrolled hyperglycemia was found in patients who experienced poor outcomes. Multiple molecular mechanisms linking hyperglycemia and SARS-CoV2 infection have been proposed including the expression of the receptor used by the virus for the entry, an altered immune response as well as an inflammatory echo.

Indeed, high blood glucose may increase viral entry and replication in vivo, possibly through the modulation of the ACE2 receptor (34-36). We will further debate this aspect later in the review.

Elevated glucose levels may also suppress the anti-viral immune response increasing the severity of viral infections. Hyperglycemia affects the innate and adaptive immune responses at several levels: it reduces neutrophil degranulation, chemotaxis and phagocytic activity, impairs complement activation and inhibits lymphocyte proliferative response $(37,38)$. As reported by Berbudi et al, hyperglycemia in diabetes is thought to cause dysfunctions of the immune response, which fails to control the spread of invading pathogens in diabetic subjects (39). It has been reported that hyperglycemia reduces macrophagic activity of neutrophils and macrophages is strongly decreased exposing patients to infection (40). During infection or inflammation, macrophages first exhibit the M1 phenotype to release TNF- $\alpha$, IL-1 $\beta$, IL-12, and IL-6 against the stimulus. But, if M1 phase continues, it can cause tissue damage. Therefore, M2 macrophages secrete high amounts of IL-10 and TGF- $\beta$ to suppress the inflammation, contribute to tissue repair, remodeling, vasculogenesis, and retain homeostasis (40). In the diabetic patients, M2 macrophages lose the capacity to suppress M1 macrophages activity and then there is a chronic inflammation making diabetic subjects more susceptible 
to infections (40). In addition, hyperglycemia activates Protein Kinase C inhibiting neutrophil migration, phagocytosis, superoxide production and microbial killing. Furthermore, hyperglycemia induces Toll-like receptor expression inhibiting neutrophil functions and apoptosis (41). As reported by Jafar et al. (41), high glucose concentrations decrease vascular dilation and increase permeability during the initial inflammatory responses, possibly through Protein Kinase C activation (41). Hyperglycemia can cause direct glycosylation of proteins and can alter the tertiary structure of complement; these changes inhibit immunoglobulin-mediated opsonization of bacteria and complement fixation to bacteria and decreases phagocytosis. Hyperglycemia also stimulates the production and release of cytokines (41). Regarding CoV infections, Kulcsar et al. examined the effects of hyperglycemia in a mouse model of MERS-CoV infection feeded with a high-fat diet (42). Upon infection with MERS-CoV, diabetic mice had a more severe disease and delayed recovery, due to a delayed inflammation that prolonged 21 days after infection. Diabetic mice had fewer inflammatory monocyte/macrophages and CD4+ T cells, which correlated with lower levels of TNF $\alpha$, and Il6 but higher levels of Il17a expression. In line with these results, patients with SARS-CoV2 are characterized by low peripheral CD4+ and CD8+ T cells counts, with high levels of pro-inflammatory Th17 CD4+ T cells, as well as elevated cytokine levels $(14,43,44)$. Thus, these data suggest that the increased disease severity observed in individuals with SARS-CoV2 infection and concomitant hyperglycemia is likely due to a dysregulated immune response, which results in more severe and prolonged pathology. Hyperglycemia may also directly affect pulmonary function such that influenza virus (34), directly increasing glucose concentrations in airway secretions (45). The high levels of glucose in pulmonary epithelial cells facilitate the virus infection and replication augmenting vasculature permeability, suggesting that hyperglycemia may increase viral replication in vivo (46). It is essential to perform a glycemic dosage of SARS-CoV2 patients to control the clinical outcomes in patients with coexistent diabetes, obesity and hyperglycemia. Obesity, as reported above, may represent another interesting factor associated with poor prognosis among COVID-19 patients. A complex cross-talk between adipose tissue and immune system with possible Implication for SARS-CoV-2 has been suggested. In particular, in physiological state, the immune cells pervade adipose tissue with a balance between immune cells and adipocytes and, in turn, adipokines production (47). In pathophysiological conditions, such as obesity, the adipose tissue is pervaded by enormous number of immune cells leading to an imbalance in the production of adipokines such as adiponectin and leptin $(48,49)$. In addition, these adipokines are involved in energy homeostasis, in glucose balance and in insulin sensitivity enhancing insulin sensitivity and glucose uptake increasing GLUT-4 translocation $(48,50)$. Likewise, the pathophysiological spectrum of adipose tissue related disorders includes type 2 diabetes, metabolic syndrome and cardiovascular diseases which are broadly associated with SARS-CoV-2 risk. Targeting the broad interaction among adipocytes released hormones, immune deregulation and comorbid related conditions can offer further perspective in tracking the SARS-CoV-2 pathogenesis.

\section{ACE2 receptor: physiological mechanisms and implication for SARS-CoV2 infection}

Coronaviruses attachment and adhesion to human target cells are mediated by a spike (S) protein which protrudes from the viral surface (7). For SARS-CoV and SARS-CoV2 a binding of the S1 region, named receptor binding domain (RBD) through the angiotensin-converting enzyme 2 (ACE2) receptor on host cells has been showed. The monocarboxypeptidase ACE2 was originally identified in 2000 as a homolog of ACE receptor $(51,52)$ and subsequently the molecular structure has been extensively described (53). ACE2 expression is broadly represented in different biological systems including airway and type II lung alveolar cells, oesophageal epithelial cells, enterocytes, cholangiocytes, myocardial cells, kidney proximal tubule cells, and bladder urothelial cells (54). In human lungs, ACE2 generates angiotensin-(I-VII) from angiotensin II by the cleavage of a single amino acid (55). Ang-(I-VII) through Mas receptor (Mas1) activation, expressed on endothelial cells, results in vasodilatory, anti-inflammatory and anti-fibrotic effects (56). Interestingly, the interaction between SARS-CoV2 and ACE2 induce the downregulation of ACE2 expression resulting in AngII accumulation with pro-inflammatory and pro-fibrotic effects $(57,58)$. In a small cohort study, levels of angiotensin II were found markedly increased in SARS-CoV2 plasma samples (59). Elevated angiotensin II levels were found in mice infected with SARS (58) or H7N9 virus finally resulting in worse clinical outcomes $(7,60,61)$ Accumulation of AngII promotes cell apoptosis through the interaction 
with receptor AT1R (61). Apoptotic stimuli can be induced through different signalling pathways. An excessive production of reactive oxygen species (ROS) upon overactivation of the AngII/AT1R/NAPDHox axis has been correlated with hypertension (62), atherosclerosis (63), and can induce apoptosis through the release of CytC from damaged mitochondria (64), activation of caspase 3 (65) or p38MAPK/JNK cascade (66). Other inflammatory mechanisms involve NF-kb activation and the transcription of cytokines such as interleukin-6, IL-1 $\beta$, tumor necrosis factor alpha (TNF $\alpha$ ) (67). High level of AngII and pro-inflammatory cytokines can then act synergistically and increase the level of cyclooxigease2 (COX2) with the consequent build-up of ROS and inflammatory prostaglandin E2 (68). The overactivation of these pathways can result in a state of hyperinflammation that is seen at late phase of SARS-CoV2 infected patient.

\section{ACE2 expression modulation: implication for anti-hypertensive and anti-diabetic treatments}

ACE2 expression is notably modified by agents acting on renin-angiotensin system (RAS). RAS inhibitors are the cornerstone of therapy of many cardiovascular and renal diseases. These drugs are broadly used also in diabetic patients for preventing the cardiovascular remodeling and diabetic nephropathy. Recently, in a multicenter retrospective study including hospitalized COVID-19 patients with previously diagnosed hypertension, the use of ACE inhibitors (ACE-Is) and Angiotensin Receptor Blockers (ARBs) was associated with lower all-cause mortality (adjusted HR, 0.42; 95\% CI, 0.19-0.92; P =0.03) and septic shock (adjusted HR, 0.36; 95\% CI, 0.16-0.84; $\mathrm{P}=0.01$ ). Similarly, in another study COVID-19 in patients with hypertension witnessed poor outcomes when compared to non-hypertensive patients; interestingly, patients under ARBs/ACE-Is were less likely to be admitted in ICU (9.3\% vs $22.9 ; \mathrm{p}=0.061)$, with a lower death rate $(4.7 \%$ vs $13.3 \%$; $\mathrm{p}=0.283)$ than treated with non ACE-Is/ARBs agents, although these differences did not reach statistical significance (69). Experimental and clinical models showed different responses from administration of agents interfering with this regulatory axis: in particular ARBs and mineralocorticoid-receptor blockers seem to increase the levels of ACE2 expression (70,71), while administration of ACE-Is even increasing cardiac ACE2 mRNA levels did not result in enhanced ACE2 activity (72). Early evidences of increased cardiac ACE2 expression was showed in rat model. After myocardial infarction, the administration of ARBs (olmesartan or losartan) increased about three-fold the ACE2 expression (73). In another experimental model, losartan administration compensated ACE2 smoke-induced reduction finally restoring the ACE/ACE2 ratio in the lung (74). In another study, increased urinary ACE2 levels were observed in hypertensive patients treated with Olmesartan (75). However, based on the above discussed mechanisms linking ACE2 expression with local anti-inflammatory, antiproliferative and antifibrotic proprieties several international societies and associations recommended against the ACE-is or sartans discontinuation in patients under chronic therapy (76) Other antidiabetic agents potentially interfere with regulation of the RAS. Thiazolidinediones are an important class of insulin sensitizers used in the treatment of type 2 diabetes. In diabetic patients, the molecular mechanisms of biological responses of thiazolidinediones are mediated through the modulation of Peroxisome Proliferators Activated Receptors (PPARs). Similar to ACEIs and ARBs, thiazolidinediones can upregulate ACE2 expression $(77,78)$ potentially exposing alveolar cell to SARS-CoV2 infection. On the other hand, PPARs are mediator of inflammation with potential immunoregulatory characteristics. Their activation prompts a reduction in inflammatory cytokines that are highly involved in SARS-CoV2 (i.e. IL6, INF $\gamma$ ) (79). Two different PPAR $\gamma$ agonists - rosiglitazone and pioglitazone (two) are insulin-mimetic drugs used in type 2 diabetes with high overall potential in reducing influenza virus infection (79). In mice infected with influenza virus pioglitazone administration resulted in improved survival based on anti-inflammatory properties $(79,80)$.

\section{Increased Inflammation in SARS-CoV2 patients with diabetes}

It is known that the subjects affected by metabolic disorders, such as obesity and diabetes, have increased risk for bacterial, mycotic, parasitic and viral infections (81). Brusfky et al. reported that diabetes and obesity as important risk factors impacting the clinical severity of coronavirus infections, including SARS-CoV2 (81). Drucker reported that acute viral respiratory infection has been linked to the rapid development of transient insulin resistance, both in otherwise healthy euglycemic normal weight or overweight individuals $(82,83)$, therefore demonstrating that infectious diseases strongly increases mortality in diabetic subjects. 
Retrospective analysis showed that mortality was increased in older diabetic patients (84). The diabetic disease is strongly associated to increased risk and worse outcomes of bacterial and viral infections attributed to a combination of dysregulated innate immunity and inflammatory responses $(85,86)$. In addition, coronavirus infection, may be complicated by secondary bacterial infection, reflecting compromise of epithelial barrier function in the lungs and in the gastrointestinal tract in diabetic subjects (82). During viral infection, the chronic inflammation and related cytokines production induces neutrophilia, coagulation activation and kidney injury leading to death of patients with SARS-CoV2 (87). Several studies showed that in diabetic patients with SARS-CoV2 absolute count of lymphocytes in peripheral blood is significantly lower, while the absolute count of neutrophils is remarkably higher (88). In addition, diabetic subjects with SARS-CoV2 has higher serum levels of various inflammation related biomarker compared to non-diabetic patients with SARS-CoV2 (7). In particular, these subjects are characterized by elevated serum levels of IL-6, TNF-a, serum ferritin and $\mathrm{C}$ reactive protein (CRP). Among of these, IL-6 are predictor of disease severity and prognosis, and its expression time is longer than other cytokines (TNF and IL-1) (89). Furthermore, Guo et al reported that in diabetic patients there is also an increase in serum ferritin indicating the activation of the monocyte-macrophage system, which is a crucial part of inflammatory storm $(87,90)$. The authors concluded that patients with diabetes are susceptible to form an inflammatory storm, which eventually lead to rapid deterioration of SARS-CoV2 (90). In diabetic patients, unbalance of the coagulative cascade resulting in D-dimer elevation has been observed. In the first time, D-dimer is increase by inflammation activating plasmin. Secondly, chronic inflammation and hypoxia, activate the thrombin and the activation of monocyte-macrophages would also secrete a mass of tissue factors and activate the exogenous coagulation pathway, which lead to an overall hypercoagulable state or even disseminated intravascular coagulation as shown by Guo et al (87). In addition, elevated D-Dimer levels are consistently reported, whereas their gradual increase during disease course is particularly associated with disease worsening (91). In conclusion, during the disease course, longitudinal evaluation of lymphocyte count dynamics and inflammatory indices, such as CRP, IL-6, and ferritin may help to identify cases with dismal prognosis and prompt intervention in order to improve outcomes.

Cytokine role in metabolic-mediated effects in SARS-COV2.

The uncontrolled production of pro-inflammatory cytokines is playing a leading role in the severity of SARSCoV2 infection. IL-6 level, for instance, has been demonstrated to correlate with disease progression and severity (92) Level of IL-6 predicts respiratory failure in hospitalized symptomatic COVID-19 patients(93). This could be accentuated in diabetic patients where the low-grade inflammation, characteristic of this pathology, can facilitate the cytokine storm caused by SARS-CoV2 infection. Among the released cytokines, IL-6, IL-1B, and TNF $\alpha$ can have a major impact on glucose metabolism insulin signaling and induce cardiovascular complications(94). For instance, CRP can be stimulated by the release of IL-6 (95). CRP can in turn aggregate and induce the activation of complement and tissue factor with the initiation of coagulation (96). It is worth noting that diabetic patients are more prone to develop coagulopathy such as disseminated intravascular coagulation (DIC) (97), a pathology that could be exacerbated in combination with SARSCoV-2 infection and result in severe outcomes (98). A further IL-6 increase in COVID-19 diabetic patients can exacerbate insulin resistance by inhibiting the autophosphorylation of the insulin receptor and the activation of PI3K and AKT pathway $(99,100)$. Like IL-6, increased levels of TNF $\alpha$ have also been shown to induce insulin resistance by impairing insulin signaling and glucose uptake in vivo (101). TNF $\alpha$ can induce the translocation of NF-kb into the nucleus and promote the transcription and release of more cytokines generating a vicious cycle. Finally, the overproduction of IL-1B can lead to B-cell dysfunction and death through the induction of nitric oxidase synthase and the excessive production of nitric oxide (102). Leptin, a pro-inflammatory cytokine chronically elevated in obese patients, has been demonstrated to be a co-factor in the progression and severity of AH1N1 influenza leading to acute lung injuries (103), and though to play a leading role in the development of insulin resistance, hypertension and cardiovascular diseases (104). Furthermore, the impaired immune response typical of obese patients can lead to poor vaccination success causing a delay in clearing the viral infection (105). Given the great impact that proinflammatory cytokines can have on glucose metabolism and insulin signaling, it is not surprising that diabetes represents a risk 
factor in SARS-CoV-2 infection. Furthermore, it could be also possible that a prolonged and acute increase of pro-inflammatory cytokines could predispose the healthy subjects that have been critically affected by COVID- 19 to develop diabetes.

\section{Conclusions}

SARS-CoV2 patients with concomitant metabolic diseases are at higher risk of worse prognosis and mortality. Several molecular machineries involving diverse biological functions such as inflammation, immunity, and epithelial defense mechanisms are at responsible for the worsening of the SARS-CoV2 infection (see Fig. 1). The management of SARS-CoV2 patients with concomitant metabolic diseases include a rigorous glucose monitoring and careful consideration of disease severity, as well as the presence of other comorbidities. A multidisciplinary team approach, including infectologists, endocrinologists, pulmonologists, psychologists, nutritionists and exercise rehabilitation specialists may be necessary to manage patients with severe phenotypes and concomitant metabolic morbidities. These considerations have major implications in public health especially for countries affected by a high incidence of metabolic diseases.

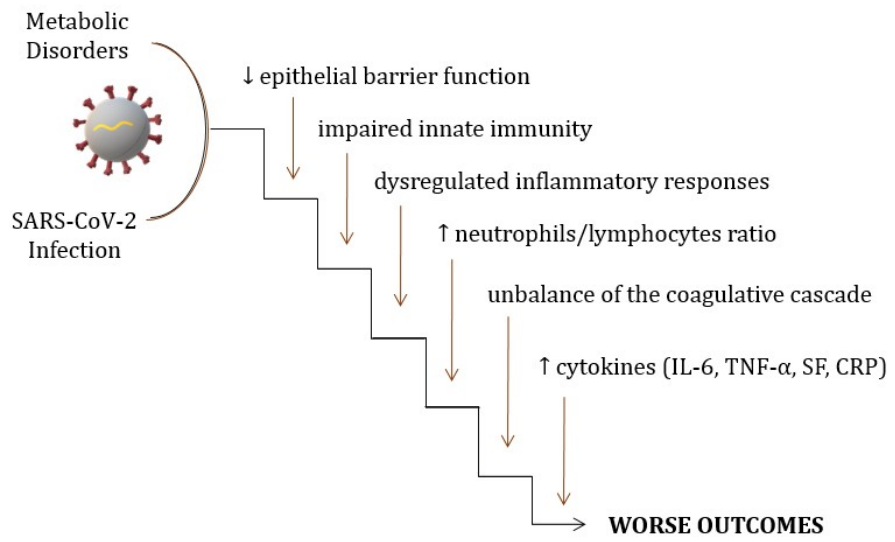

Fig. 1: Molecular machineries responsible for the worsening of the SARS-CoV2 phenotype and prognosis in patients with concomitant metabolic diseases. Biological functions such as inflammation, immunity, and epithelial defense mechanisms are involved.

\section{References}

1. Columbus C, Brust KB, Arroliga AC. 2019 novel coronavirus: an emerging global threat. Proc (Bayl Univ Med Cent). 2020 Apr;33(2):209-12.

2. https://www.who.int/docs/default-source/coronaviruse/situation-reports/20200414-sitrep-85-SARSCoV2-19.pdf?sfvrsn=7b8629bb_4).

3. www.epicentro.iss.it/coronavirus/bollettino/Infografica_15aprile\%20ITA.pdf.

4. Singhal T. A Review of Coronavirus Disease-2019 (COVID-19). Indian J Pediatr. 2020 Apr;87(4):281-6.

5. Walls AC, Park Y-J, Tortorici MA, Wall A, McGuire AT, Veesler D. Structure, Function, and Antigenicity of the SARS-CoV-2 Spike Glycoprotein. Cell. 2020 Apr;181(2):281-292.e6.

6. Zhang L, Lin D, Sun X, Curth U, Drosten C, Sauerhering L, et al. Crystal structure of SARS-CoV-2 main protease provides a basis for design of improved $\alpha$-ketoamide inhibitors. Science. 2020 Apr;368(6489):409-12.

7. Yang J, Zheng Y, Gou X, Pu K, Chen Z, Guo Q, et al. Prevalence of comorbidities and its effects in 
coronavirus disease 2019 patients: A systematic review and meta-analysis. Int J Infect Dis IJID Off Publ Int Soc Infect Dis. 2020 Mar;94:91-5.

8. Wang D, Hu B, Hu C, Zhu F, Liu X, Zhang J, et al. Clinical Characteristics of 138 Hospitalized Patients With 2019 Novel Coronavirus-Infected Pneumonia in Wuhan, China. JAMA. 2020 Feb;

9. Gao H-N, Lu H-Z, Cao B, Du B, Shang H, Gan J-H, et al. Clinical findings in 111 cases of influenza A (H7N9) virus infection. N Engl J Med. 2013 Jun;368(24):2277-85.

10. Alqahtani FY, Aleanizy FS, Ali El Hadi Mohamed R, Alanazi MS, Mohamed N, Alrasheed MM, et al. Prevalence of comorbidities in cases of Middle East respiratory syndrome coronavirus: a retrospective study. Epidemiol Infect. 2018 Nov;147:1-5.

11. Garbati MA, Fagbo SF, Fang VJ, Skakni L, Joseph M, Wani TA, et al. A Comparative Study of Clinical Presentation and Risk Factors for Adverse Outcome in Patients Hospitalised with Acute Respiratory Disease Due to MERS Coronavirus or Other Causes. PLoS One. 2016;11(11):e0165978.

12. Rivers CM, Majumder MS, Lofgren ET. Risks of Death and Severe Disease in Patients With Middle East Respiratory Syndrome Coronavirus, 2012-2015. Am J Epidemiol. 2016 Sep;184(6):460-4.

13. Guan W-J, Liang W-H, Zhao Y, Liang H-R, Chen Z-S, Li Y-M, et al. Comorbidity and its impact on 1590 patients with Covid-19 in China: A Nationwide Analysis. Eur Respir J. 2020 Mar;

14. Guan W-J, Zhong N-S. Clinical Characteristics of Covid-19 in China. Reply. Vol. 382, The New England journal of medicine. United States; 2020.

15. Onder G, Rezza G, Brusaferro S. Case-Fatality Rate and Characteristics of Patients Dying in Relation to COVID-19 in Italy. JAMA. 2020 Mar;

16. Yang X, Yu Y, Xu J, Shu H, Xia J, Liu H, et al. Clinical course and outcomes of critically ill patients with SARS-CoV-2 pneumonia in Wuhan, China: a single-centered, retrospective, observational study. Lancet Respir Med. 2020 Feb;

17. Chen N, Zhou M, Dong X, Qu J, Gong F, Han Y, et al. Epidemiological and clinical characteristics of 99 cases of 2019 novel coronavirus pneumonia in Wuhan, China: a descriptive study. Lancet (London, England). 2020 Feb;395(10223):507-13.

18. Chen C-Y, Lee C-H, Liu C-Y, Wang J-H, Wang L-M, Perng R-P. Clinical features and outcomes of severe acute respiratory syndrome and predictive factors for acute respiratory distress syndrome. J Chin Med Assoc. 2005 Jan;68(1):4-10.

19. Tsui PT, Kwok ML, Yuen H, Lai ST. Severe acute respiratory syndrome: clinical outcome and prognostic correlates. Emerg Infect Dis. 2003 Sep;9(9):1064-9.

20. Chan JCK, Tsui ELH, Wong VCW. Prognostication in severe acute respiratory syndrome: a retrospective time-course analysis of 1312 laboratory-confirmed patients in Hong Kong. Respirology. 2007 Jul;12(4):53142.

21. Booth CM, Matukas LM, Tomlinson GA, Rachlis AR, Rose DB, Dwosh HA, et al. Clinical features and short-term outcomes of 144 patients with SARS in the greater Toronto area. JAMA. 2003 Jun;289(21):28019 .

22. Liu C-L, Lu Y-T, Peng M-J, Chen P-J, Lin R-L, Wu C-L, et al. Clinical and laboratory features of severe acute respiratory syndrome vis-a-vis onset of fever. Chest. 2004 Aug;126(2):509-17.

23. Assiri A, Al-Tawfiq JA, Al-Rabeeah AA, Al-Rabiah FA, Al-Hajjar S, Al-Barrak A, et al. Epidemiological, demographic, and clinical characteristics of 47 cases of Middle East respiratory syndrome coronavirus disease from Saudi Arabia: a descriptive study. Lancet Infect Dis. 2013 Sep;13(9):752-61. 
24. Mehra MR, Desai SS, Kuy S, Henry TD, Patel AN. Cardiovascular Disease, Drug Therapy, and Mortality in Covid-19. N Engl J Med. 2020 May;

25. Lighter J, Phillips M, Hochman S, Sterling S, Johnson D, Francois F, et al. Obesity in patients younger than 60 years is a risk factor for Covid-19 hospital admission. Clin Infect Dis an Off Publ Infect Dis Soc Am. 2020 Apr;

26. Chan JWM, Ng CK, Chan YH, Mok TYW, Lee S, Chu SYY, et al. Short term outcome and risk factors for adverse clinical outcomes in adults with severe acute respiratory syndrome (SARS). Thorax. 2003 Aug;58(8):686-9.

27. https://www.epicentro.iss.it/en/coronavirus/sars-cov-2-analysis-of-deaths.

28. Li B, Yang J, Zhao F, Zhi L, Wang X, Liu L, et al. Prevalence and impact of cardiovascular metabolic diseases on COVID-19 in China. Clin Res Cardiol. 2020 May;109(5):531-8.

29. Fadini GP, Morieri ML, Longato E, Avogaro A. Prevalence and impact of diabetes among people infected with SARS-CoV-2. Journal of endocrinological investigation. Italy; 2020.

30. Sun Y, Wang Q, Yang G, Lin C, Zhang Y, Yang P. Weight and prognosis for influenza A(H1N1)pdm09 infection during the pandemic period between 2009 and 2011: a systematic review of observational studies with meta-analysis. Infect Dis (London, England). 2016;48(11-12):813-22.

31. Carter SJ, Baranauskas MN, Fly AD. Considerations for obesity, vitamin D, and physical activity amidst the COVID-19 pandemic. Obesity (Silver Spring). 2020 Apr;

32. Remuzzi A, Remuzzi G. COVID-19 and Italy: what next? Lancet (London, England). 2020 Apr;395(10231):1225-8.

33. Li X, Xu S, Yu M, Wang K, Tao Y, Zhou Y, et al. Risk factors for severity and mortality in adult COVID-19 inpatients in Wuhan. J Allergy Clin Immunol. 2020 Apr;

34. Hulme KD, Gallo LA, Short KR. Influenza Virus and Glycemic Variability in Diabetes: A Killer Combination? Front Microbiol. 2017;8:861.

35. Wysocki J, Ye M, Soler MJ, Gurley SB, Xiao HD, Bernstein KE, et al. ACE and ACE2 activity in diabetic mice. Diabetes. 2006 Jul;55(7):2132-9.

36. Longato E, Di Camillo B, Sparacino G, Saccavini C, Avogaro A, Fadini GP. Diabetes diagnosis from administrative claims and estimation of the true prevalence of diabetes among 4.2 million individuals of the Veneto region (North East Italy). Nutr Metab Cardiovasc Dis. 2020 Jan;30(1):84-91.

37. Stegenga ME, van der Crabben SN, Blümer RME, Levi M, Meijers JCM, Serlie MJ, et al. Hyperglycemia enhances coagulation and reduces neutrophil degranulation, whereas hyperinsulinemia inhibits fibrinolysis during human endotoxemia. Blood. 2008 Jul;112(1):82-9.

38. Moutschen MP, Scheen AJ, Lefebvre PJ. Impaired immune responses in diabetes mellitus: analysis of the factors and mechanisms involved. Relevance to the increased susceptibility of diabetic patients to specific infections. Diabete Metab. 1992;18(3):187-201.

39. Berbudi A, Rahmadika N, Cahyadi AI, Ruslami R. Type 2 Diabetes and its Impact on the Immune System. Curr Diabetes Rev. 2019 Oct;

40. Shapouri-Moghaddam A, Mohammadian S, Vazini H, Taghadosi M, Esmaeili S-A, Mardani F, et al. Macrophage plasticity, polarization, and function in health and disease. J Cell Physiol. 2018 Sep;233(9):642540.

41. Jafar N, Edriss H, Nugent K. The Effect of Short-Term Hyperglycemia on the Innate Immune System. Am J Med Sci. 2016 Feb;351(2):201-11. 
42. Kulcsar KA, Coleman CM, Beck SE, Frieman MB. Comorbid diabetes results in immune dysregulation and enhanced disease severity following MERS-CoV infection. JCI insight. 2019 Oct;4(20).

43. Wu C, Chen X, Cai Y, Xia J, Zhou X, Xu S, et al. Risk Factors Associated With Acute Respiratory Distress Syndrome and Death in Patients With Coronavirus Disease 2019 Pneumonia in Wuhan, China. JAMA Intern Med. 2020 Mar;

44. Xu Z, Shi L, Wang Y, Zhang J, Huang L, Zhang C, et al. Pathological findings of COVID-19 associated with acute respiratory distress syndrome. Vol. 8, The Lancet. Respiratory medicine. 2020. p. 420-2.

45. Philips BJ, Redman J, Brennan A, Wood D, Holliman R, Baines D, et al. Glucose in bronchial aspirates increases the risk of respiratory MRSA in intubated patients. Thorax. 2005 Sep;60(9):761-4.

46. Popov D, Simionescu M. Alterations of lung structure in experimental diabetes, and diabetes associated with hyperlipidaemia in hamsters. Eur Respir J. 1997 Aug;10(8):1850-8.

47. Exley MA, Hand L, O'Shea D, Lynch L. Interplay between the immune system and adipose tissue in obesity. J Endocrinol. 2014 Nov;223(2):R41-8.

48. Polito R, Nigro E, Messina A, Monaco ML, Monda V, Scudiero O, et al. Adiponectin and Orexin-A as a Potential Immunity Link Between Adipose Tissue and Central Nervous System. Front Physiol. 2018;9:982.

49. Nigro E, Stiuso P, Matera MG, Monaco ML, Caraglia M, Maniscalco M, et al. The anti-proliferative effects of adiponectin on human lung adenocarcinoma A549cells and oxidative stress involvement. Pulm Pharmacol Ther. 2019 Jan;

50. Pecoraro A, Nigro E, Polito R, Monaco ML, Scudiero O, Mormile I, et al. Total and High Molecular Weight Adiponectin Expression Is Decreased in Patients with Common Variable Immunodeficiency: Correlation with Ig Replacement Therapy. Front Immunol. 2017;8:895.

51. Tipnis SR, Hooper NM, Hyde R, Karran E, Christie G, Turner AJ. A human homolog of angiotensinconverting enzyme. Cloning and functional expression as a captopril-insensitive carboxypeptidase. J Biol Chem. 2000 Oct;275(43):33238-43.

52. Donoghue M, Hsieh F, Baronas E, Godbout K, Gosselin M, Stagliano N, et al. A novel angiotensinconverting enzyme-related carboxypeptidase (ACE2) converts angiotensin I to angiotensin 1-9. Circ Res. 2000 Sep;87(5):E1-9.

53. Yan R, Zhang Y, Li Y, Xia L, Guo Y, Zhou Q. Structural basis for the recognition of SARS-CoV-2 by full-length human ACE2. Science. 2020 Mar;367(6485):1444-8.

54. Xu H, Zhong L, Deng J, Peng J, Dan H, Zeng X, et al. High expression of ACE2 receptor of 2019-nCoV on the epithelial cells of oral mucosa. Int J Oral Sci. 2020 Feb;12(1):8.

55. Gaddam RR, Chambers S, Bhatia M. ACE and ACE2 in inflammation: a tale of two enzymes. Inflamm Allergy Drug Targets. 2014;13(4):224-34.

56. Hemnes AR, Rathinasabapathy A, Austin EA, Brittain EL, Carrier EJ, Chen X, et al. A potential therapeutic role for angiotensin-converting enzyme 2 in human pulmonary arterial hypertension. Eur Respir J. 2018 Jun;51(6).

57. Kuba K, Imai Y, Rao S, Gao H, Guo F, Guan B, et al. A crucial role of angiotensin converting enzyme 2 (ACE2) in SARS coronavirus-induced lung injury. Nat Med. 2005 Aug;11(8):875-9.

58. Imai Y, Kuba K, Rao S, Huan Y, Guo F, Guan B, et al. Angiotensin-converting enzyme 2 protects from severe acute lung failure. Nature. 2005 Jul;436(7047):112-6.

59. Liu Y, Yang Y, Zhang C, Huang F, Wang F, Yuan J, et al. Clinical and biochemical indexes from 2019-nCoV infected patients linked to viral loads and lung injury. Sci China Life Sci. 2020 Mar;63(3):364-74. 
60. Yang P, Gu H, Zhao Z, Wang W, Cao B, Lai C, et al. Angiotensin-converting enzyme 2 (ACE2) mediates influenza H7N9 virus-induced acute lung injury. Sci Rep. 2014 Nov;4:7027.

61. Papp M, Li X, Zhuang J, Wang R, Uhal BD. Angiotensin receptor subtype AT(1) mediates alveolar epithelial cell apoptosis in response to ANG II. Am J Physiol Lung Cell Mol Physiol. 2002 Apr;282(4):L7138.

62. Dikalova A, Clempus R, Lassègue B, Cheng G, McCoy J, Dikalov S, et al. Nox1 overexpression potentiates angiotensin II-induced hypertension and vascular smooth muscle hypertrophy in transgenic mice. Circulation. 2005 Oct;112(17):2668-76.

63. Jones ES, Vinh A, McCarthy CA, Gaspari TA, Widdop RE. AT2 receptors: functional relevance in cardiovascular disease. Pharmacol Ther. 2008 Dec;120(3):292-316.

64. Dikalov SI, Ungvari Z. Role of mitochondrial oxidative stress in hypertension. Am J Physiol Heart Circ Physiol. 2013 Nov;305(10):H1417-27.

65. Xue D, Li Y, Jiang Z, Deng G, Li M, Liu X, et al. A ROS-dependent and Caspase-3-mediated apoptosis in sheep bronchial epithelial cells in response to Mycoplasma Ovipneumoniae infections. Vet Immunol Immunopathol. 2017 May;187:55-63.

66. Cardoso VG, Gonçalves GL, Costa-Pessoa JM, Thieme K, Lins BB, Casare FAM, et al. Angiotensin II-induced podocyte apoptosis is mediated by endoplasmic reticulum stress/PKC- $\delta / \mathrm{p} 38 \mathrm{MAPK}$ pathway activation and trough increased $\mathrm{Na}(+) / \mathrm{H}(+)$ exchanger isoform 1 activity. BMC Nephrol. 2018 Jul;19(1):179.

67. Zhang X, Wu M, Jiang H, Hao J, Zhang Q, Zhu Q, et al. Angiotensin II upregulates endothelial lipase expression via the NF-kappa B and MAPK signaling pathways. PLoS One. 2014;9(9):e107634.

68. Kawahara K, Hohjoh H, Inazumi T, Tsuchiya S, Sugimoto Y. Prostaglandin E2-induced inflammation: Relevance of prostaglandin E receptors. Biochim Biophys Acta. 2015 Apr;1851(4):414-21.

69. Yang G, Tan Z, Zhou L, Yang M, Peng L, Liu J, et al. Effects Of ARBs And ACEIs On Virus Infection, Inflammatory Status And Clinical Outcomes In COVID-19 Patients With Hypertension: A Single Center Retrospective Study. Hypertens (Dallas, Tex 1979). 2020 Apr;

70. Zhong J-C, Ye J-Y, Jin H-Y, Yu X, Yu H-M, Zhu D-L, et al. Telmisartan attenuates aortic hypertrophy in hypertensive rats by the modulation of ACE2 and profilin-1 expression. Regul Pept. 2011 Jan;166(1-3):90-7.

71. Keidar S, Gamliel-Lazarovich A, Kaplan M, Pavlotzky E, Hamoud S, Hayek T, et al. Mineralocorticoid receptor blocker increases angiotensin-converting enzyme 2 activity in congestive heart failure patients. Circ Res. 2005 Oct; $97(9): 946-53$.

72. Ferrario CM, Jessup J, Chappell MC, Averill DB, Brosnihan KB, Tallant EA, et al. Effect of angiotensinconverting enzyme inhibition and angiotensin II receptor blockers on cardiac angiotensin-converting enzyme 2. Circulation. 2005 May;111(20):2605-10.

73. Ishiyama Y, Gallagher PE, Averill DB, Tallant EA, Brosnihan KB, Ferrario CM. Upregulation of angiotensin-converting enzyme 2 after myocardial infarction by blockade of angiotensin II receptors. Hypertens (Dallas, Tex 1979). 2004 May;43(5):970-6.

74. Yuan Y-M, Luo L, Guo Z, Yang M, Ye R-S, Luo C. Activation of renin-angiotensin-aldosterone system (RAAS) in the lung of smoking-induced pulmonary arterial hypertension (PAH) rats. J Renin Angiotensin Aldosterone Syst. 2015 Jun;16(2):249-53.

75. Furuhashi M, Moniwa N, Mita T, Fuseya T, Ishimura S, Ohno K, et al. Urinary angiotensin-converting enzyme 2 in hypertensive patients may be increased by olmesartan, an angiotensin II receptor blocker. Am J Hypertens. 2015 Jan;28(1):15-21. 
76. Perrotta F, Matera MG, Cazzola M, Bianco A. Severe respiratory SARS-CoV2 infection: Does ACE2 receptor matter? Respir Med. 2020;168(April):105996.

77. Ali RM, Al-Shorbagy MY, Helmy MW, El-Abhar HS. Role of Wnt4/ $\beta$-catenin, Ang II/TGF $\beta$, ACE2, $\mathrm{NF}-\chi \mathrm{B}$, and IL-18 in attenuating renal ischemia/reperfusion-induced injury in rats treated with Vit D and pioglitazone. Eur J Pharmacol. 2018 Jul;831:68-76.

78. Zhang W, Li C, Liu B, Wu R, Zou N, Xu Y-Z, et al. Pioglitazone upregulates hepatic angiotensin converting enzyme 2 expression in rats with steatohepatitis. Ann Hepatol. 2013;12(6):892-900.

79. Darwish I, Mubareka S, Liles WC. Immunomodulatory therapy for severe influenza. Expert Rev Anti Infect Ther. $2011 \mathrm{Jul} ; 9(7): 807-22$.

80. Moseley CE, Webster RG, Aldridge JR. Peroxisome proliferator-activated receptor and AMP-activated protein kinase agonists protect against lethal influenza virus challenge in mice. Influenza Other Respi Viruses. 2010 Sep;4(5):307-11.

81. Brufsky A. Hyperglycemia, hydroxychloroquine, and the COVID-19 pandemic. J Med Virol. 2020 Apr;

82. Drucker DJ. Coronavirus Infections and Type 2 Diabetes-Shared Pathways with Therapeutic Implications. Endocr Rev. 2020 Jun;41(3).

83. Šestan M, Marinović S, Kavazović I, Cekinović Đ, Wueest S, Turk Wensveen T, et al. Virus-Induced Interferon- $\gamma$ Causes Insulin Resistance in Skeletal Muscle and Derails Glycemic Control in Obesity. Immunity. 2018 Jul;49(1):164-177.e6.

84. Rao Kondapally Seshasai S, Kaptoge S, Thompson A, Di Angelantonio E, Gao P, Sarwar N, et al. Diabetes mellitus, fasting glucose, and risk of cause-specific death. N Engl J Med. 2011 Mar;364(9):829-41.

85. van Crevel R, van de Vijver S, Moore DAJ. The global diabetes epidemic: what does it mean for infectious diseases in tropical countries? lancet Diabetes Endocrinol. 2017 Jun;5(6):457-68.

86. Hodgson K, Morris J, Bridson T, Govan B, Rush C, Ketheesan N. Immunological mechanisms contributing to the double burden of diabetes and intracellular bacterial infections. Immunology. 2015 Feb;144(2):17185.

87. Guo W, Li M, Dong Y, Zhou H, Zhang Z, Tian C, et al. Diabetes is a risk factor for the progression and prognosis of COVID-19. Diabetes Metab Res Rev. 2020 Mar;e3319.

88. Shah BR, Hux JE. Quantifying the risk of infectious diseases for people with diabetes. Diabetes Care. 2003 Feb;26(2):510-3.

89. Huang C, Wang Y, Li X, Ren L, Zhao J, Hu Y, et al. Clinical features of patients infected with 2019 novel coronavirus in Wuhan, China. Lancet (London, England). 2020 Feb;395(10223):497-506.

90. Muniyappa R, Gubbi S. COVID-19 pandemic, coronaviruses, and diabetes mellitus. Am J Physiol Endocrinol Metab. 2020 May;318(5):E736-41.

91. Terpos E, Ntanasis-Stathopoulos I, Elalamy I, Kastritis E, Sergentanis TN, Politou M, et al. Hematological findings and complications of COVID-19. Am J Hematol. 2020 Apr;

92. Liu B, Li M, Zhou Z, Guan X, Xiang Y. Can we use interleukin-6 (IL-6) blockade for coronavirus disease 2019 (COVID-19)-induced cytokine release syndrome (CRS)? J Autoimmun. 2020 Apr;102452.

93. Herold T, Jurinovic V, Arnreich C, Hellmuth JC, von Bergwelt-Baildon M, Klein M, et al. Level of IL-6 predicts respiratory failure in hospitalized symptomatic COVID-19 patients. medRxiv. 2020 Jan;2020.04.01.20047381.

94. Perrotta F, Nigro E, Mollica M, Costigliola A, D'Agnano V, Daniele A, et al. Pulmonary Hypertension and Obesity: Focus on Adiponectin. Int J Mol Sci. 2019 Feb;20(4). 
95. Devaraj S, Singh U, Jialal I. The evolving role of C-reactive protein in atherothrombosis. Clin Chem. 2009 Feb;55(2):229-38.

96. Fay WP. Linking inflammation and thrombosis: Role of C-reactive protein. World J Cardiol. 2010 Nov;2(11):365-9.

97. Nogami K, Muraki I, Imano H, Iso H. Risk of disseminated intravascular coagulation in patients with type 2 diabetes mellitus: retrospective cohort study. BMJ Open. 2017 Jan;7(1):e013894.

98. Kollias A, Kyriakoulis KG, Dimakakos E, Poulakou G, Stergiou GS, Syrigos K. Thromboembolic risk and anticoagulant therapy in COVID-19 patients: Emerging evidence and call for action. Br J Haematol. 2020 Apr;

99. Senn JJ, Klover PJ, Nowak IA, Mooney RA. Interleukin-6 induces cellular insulin resistance in hepatocytes. Diabetes. 2002 Dec;51(12):3391-9.

100. Klover PJ, Zimmers TA, Koniaris LG, Mooney RA. Chronic exposure to interleukin-6 causes hepatic insulin resistance in mice. Diabetes. 2003 Nov;52(11):2784-9.

101. Plomgaard P, Bouzakri K, Krogh-Madsen R, Mittendorfer B, Zierath JR, Pedersen BK. Tumor necrosis factor-alpha induces skeletal muscle insulin resistance in healthy human subjects via inhibition of Akt substrate 160 phosphorylation. Diabetes. 2005 Oct;54(10):2939-45.

102. Dinarello CA. Blocking interleukin- $1 \beta$ in acute and chronic autoinflammatory diseases. J Intern Med. 2011 Jan;269(1):16-28.

103. Zhang AJX, To KKW, Li C, Lau CCY, Poon VKM, Chan CCS, et al. Leptin mediates the pathogenesis of severe 2009 pandemic influenza $\mathrm{A}(\mathrm{H} 1 \mathrm{~N} 1)$ infection associated with cytokine dysregulation in mice with diet-induced obesity. J Infect Dis. 2013 Apr;207(8):1270-80.

104. Hou N, Luo J-D. Leptin and cardiovascular diseases. Clin Exp Pharmacol Physiol. 2011 Dec;38(12):90513.

105. Karlsson EA, Hertz T, Johnson C, Mehle A, Krammer F, Schultz-Cherry S. Obesity Outweighs Protection Conferred by Adjuvanted Influenza Vaccination. MBio. 2016 Aug;7(4). 